\title{
Strategic Delegation in Monetary Unions
}

\author{
V. V. Chari, Larry E. Jones, and Ramon Marimon* \\ April 2004 \\ Barcelona Economics WP 135
}

\begin{abstract}
In monetary unions, monetary policy is typically made by delegates of the member countries. This procedure raises the possibility of strategic delegation- that countries may choose the types of delegates to influence outcomes in their favor. We show that without commitment in monetary policy, strategic delegation arises if and only if three conditions are met: shocks affecting individual countries are not perfectly correlated, risk-sharing across countries is imperfect, and the Phillips Curve is nonlinear. Moreover, inflation rates are inefficiently high. We argue that ways of solving the commitment problem, including the emphasis on price stability in the agreements constituting the European Union are especially valuable when strategic delegation is a problem.
\end{abstract}

JEL Nos: E58, E61.

*Chari and Jones: Department of Economics, University of Minnesota and Federal Reserve Bank of Minneapolis; Marimon: Universitat Pompeu Fabra, CREi and CREA. The views expressed herein are those of the authors and not necessarily those of the Federal Reserve Bank of Minneapolis or the Federal Reserve System. 


\section{Introduction}

Over the last decade or so, interest has grown in the design of monetary unions - groups of countries which share a central monetary authority. In such unions, monetary policy is typically made by a committee of delegates appointed by the governments of the countries in the union. This procedure for making monetary policy raises the possibility that each government in the monetary union may choose the types of delegates strategically in an attempt to influence outcomes in its favor. We call outcomes in which the preferences of delegates are systematically different from the preferences of those who appoint them, strategic delegation. In this paper, we ask when strategic delegation is likely to occur and when it leads to inefficient outcomes in a monetary union. We show that outcomes are inefficient if and only if three conditions are satisfied: shocks affecting countries are not perfectly correlated, risk sharing mechanisms are imperfect and the Phillips curve is nonlinear in the sense that inflation has a larger effect on output in recessions than in booms.

Our model is a multicountry version of the classic models of monetary policy in Kydland-Prescott (1977), Barro-Gordon (1983), and Rogoff (1985). In the model, as in Rogoff, governments first choose the types of their delegates, then the shocks are realized and finally the delegates bargain over the choice of a common inflation rate for the countries in the union. We show that two forces lead to strategic delegation: the commitment problem identified by Kydland-Prescott (1977) and a free rider problem, similar to that in Chari, Jones and Marimon (1997). As in Rogoff, governments have an incentive to solve the commitment problem by delegating monetary policy to central bankers who are tougher on inflation than are the governments. In contrast, the free rider problem we identify provides incentives for governments to appoint delegates who are soft on inflation. ${ }^{1}$ If shocks affecting individual countries are not perfectly correlated, risk-sharing is imperfect, and the Phillips Curve is nonlinear, the free rider problem dominates leading to an inefficiently high level of inflation. Moreover, the level of inflation is higher than it would be if each country had an independent monetary authority.

The free rider problem in our model is that, once shocks are realized and

\footnotetext{
${ }^{1}$ As is conventional in this literature, we refer to representatives who are tough on inflation as 'conservative' and those who are soft as 'liberal.'
} 
it is known which economies are in recessions and which are in booms, the benefits accrue disproportionately to countries in recessions but the costs of high inflation are borne by all countries in the union. This feature implies that each government has an incentive to appoint a relatively liberal delegate. The reason is that such a delegate will attempt to raise inflation rates when that country's economy is in a recession, and with a nonlinear Phillips curve, will not attempt to raise inflation rates by much in booms. If shocks are perfectly correlated or if risk-sharing across countries is perfect, the free rider problem disappears because the costs and benefits of high inflation are spread evenly across all countries. If the Phillips curve is linear, a liberal delegate has the same incentives, at the margin, to raise inflation in recessions as well as booms. In this case, the commitment problem dominates the free rider problem and governments' incentives to appoint liberal delegates are weaker.

Most of the ingredients in our model are standard in the literature. Preferences over output and inflation are assumed to be quadratic. We model the relative conservatism of central bankers as a type parameter which affects the weight on output relative to that on inflation. The timing is as follows. Governments choose the type of delegate to represent them. Then nominal wages are chosen by workers and are assumed to be sticky. Shocks are realized and it becomes known which countries are in recessions. Output in recessions is a decreasing function of the real wage rate, or alternatively rises with a rise in the price level. Output in booms is not affected by rises in the price level. This extreme form of nonlinearity makes the exposition easier. We model the outcome of the bargaining between the delegates as the solution to the Nash bargaining problem.

These features lead to the commitment problem and the free rider problem. The key ingredient generating the commitment problem is that wages are sticky. As is well known, if wages were perfectly flexible, the commitment problem disappears. Without a commitment problem, the free rider problem disappears. With a commitment problem, the free rider problem arises if three conditions are met: shocks are imperfectly correlated, insurance is incomplete insurance or labor mobility between the countries in the union is imperfect, and the Phillips Curve is asymmetric. To see that these features play a key role, we consider variants of the model with perfectly correlated shocks, complete insurance/complete labor mobility and with a linear Phillips curve. In each case, we show that the severity of the free rider problem is vastly reduced, and that inflation and output are at their efficient levels. 
This paper is primarily about the costs of a monetary union arising from the free rider problem associated with a joint choice of monetary policy. What our results show is that if economic linkages are high in the sense that mechanisms to provide insurance are well developed, or in the sense that labor mobility is high, or in the sense that shocks are highly correlated, strategic delegation costs are correspondingly low. Although we do not specifically model the benefits of a monetary union here, our results have some implications about the optimal size of currency unions. Specifically, if economic linkages are high the costs of forming a monetary union are correspondingly low.

The economic linkages our analysis emphasizes are markets for sharing risk and factor mobility. Markets for sharing risks may well be poorly developed if regions are not already part of a political union. Labor mobility is typically higher within countries than across. These considerations might well help explain why strategic delegation is not thought to be a problem in the US even though central bank delegates are appointed from different regions in the country. In the absence of a political union, however, these economic links are weaker and strategic delegation should be expected to be more of a problem. Our results can also be interpreted as suggesting that when economic linkages are poor, other ways of solving the commitment problem are especially valuable. One way of attempting to solve the commitment problem is found in the treaties setting up the European Monetary Union. These treaties emphasize the primacy of price stability in the conduct of monetary policy. Our analysis suggests that such provisions are especially valuable if economic linkages are weak.

An extensive literature has analyzed policy making in monetary unions. Most closely related to our work here is the work of Chari and Kehoe (2002) and (2003). They emphasize that lack of commitment in monetary policy leads to free rider problems in other policy making, including fiscal policy, labor market policy and banking policy. In their models, in contrast to the work here, monetary policy is set by a benevolent policy maker who seeks to maximize average welfare. Thus, they do not consider the strategic delegation problem which is at the heart of our analysis. Our research is also related to a literature on fiscal policy in monetary unions including Beetsma and Uhlig (1999), Dixit and Lambertini (2001), Cooper and Kempf (2001) and Uhlig (2002). Of these papers, the last two are the most closely related to our work here. Cooper and Kempf focus mostly on the gains to forming a monetary union with commitment. They go on to show that when there is 
no commitment the monetary union may be undesirable. In Uhlig's model, there is a free-rider problem in fiscal policy. This free-rider problem ends up reducing welfare, but does not raise the inflation rate.

\section{A Benchmark Model of Strategic Delega- tion}

Consider an economy with $N$ counties, indexed by $i$, and $N$ states denoted by $s, s=1, \ldots, N$. For simplicity, we assume that all states are equally likely, so that the probability of each state is $1 / N$. We interpret the outcome, $s=i$, as the realization where country $i$ is in a recession, while in the other countries, output is at its 'normal' level. Inflation is assumed to be the same across all countries in every state. Let $\pi(s)$ denote the common inflation rate in state $s$. Output (or equivalently in this model, consumption) in country $i$ in state $s$ is denoted by $y_{i}(s)$, and we will use $\bar{y}$ to denote the full employment, or 'normal' level of output in all countries.

Output is given as follows,

$$
y_{i}\left(s_{i}\right)=\min \left[\bar{y}+\pi\left(s_{i}\right)-w_{i}-\delta, \bar{y}\right],
$$

and

$$
y_{j}\left(s_{i}\right)=\bar{y} \text { if } j \neq i,
$$

where $w_{i}$ denotes the wage rate in country $i$. In equilibrium, the wage rates turn out to be the same in all countries. To make the exposition easier, we will assume that the wage rates are the same and denote these wage rates by $w$. If the state is $s_{i}$, country $i$ may be thought of as being in a recession in the sense that output in country $i$ falls by $\delta$ if the inflation rate is zero and, in such a state, output tends to respond to changes in the inflation rate $\pi(s)$. In state $s_{i}$, output in countries $j \neq i$ is higher and is not affected by the inflation rate.

We assume that preferences of the governments in country $i$ are given by:

$$
U_{i}=\frac{1}{N} \sum_{j=1}^{N}\left[-\frac{1}{2}\left(y_{i}\left(s_{j}\right)-\bar{y}\right)^{2}-\frac{1}{2} \pi\left(s_{j}\right)^{2}\right] .
$$


The government of country $i$ chooses a delegate of type $\theta_{i}$ to send as its member to the monetary union. At the time that the inflation rate is chosen, this delegate has preferences given by:

$$
U_{i}\left(s_{j}, \theta_{i}\right)=-\frac{\theta_{i}}{2}\left(y_{i}\left(s_{j}\right)-\bar{y}\right)^{2}-\frac{1}{2} \pi\left(s_{j}\right)^{2} .
$$

Thus, the lower is $\theta_{i}$, the more emphasis this delegate places on inflation, and the choice of $\theta_{i}=1$, corresponds to governments 'choosing themselves,' or to no strategic delegation.

We assume that wage setters' preferences are such that they desire to set nominal wages so that expected real wages are equal to a constant, normalized to be zero.

The timing is as follows.

Game Theoretic Structure of the Model

Stage I: Governments simultaneously choose their delegate types $\left(\theta_{i}\right)$.

Stage II: Workers in each country simultaneously choose wage rates, $w_{i}$.

Stage III: The state, $s$, is realized.

Stage IV: The monetary authority chooses an inflation rate $\pi(s)$.

We assume that at Stage IV, the outcome is determined by an equally weighted Nash bargaining rule that maximizes the sum of delegate payoffs.

The strategies in this game are denoted as follows. The monetary authority's strategy is denoted by $\pi(s, \theta, w)$ where $\theta$ denotes the vector of delegate types. The workers' strategies are given by $w(\theta)$, and the governments each choose $\theta_{i}, i=1,2, \ldots, N$. A subgame perfect equilibrium is defined in the usual way.

\section{Characterizing Equilibrium Strategies}

We solve the game using backward induction. Consider first the situation in stage IV in state $s_{i}$. At this stage $y_{i}\left(s_{j}\right)=\bar{y}$ for $j \neq i$ so that the sum of delegate payoffs is

$$
U=-\frac{\theta_{i}}{2}\left(y_{i}\left(s_{i}\right)-\bar{y}\right)^{2}-\frac{N}{2} \pi\left(s_{i}\right)^{2}
$$

Substituting from (1) for output, the first order condition for the choice of $\pi$ is given by:

$$
-\theta_{i}\left(\pi\left(s_{i}\right)-w-\delta\right)-N \pi\left(s_{i}\right)=0 .
$$


Thus, it follows that in equilibrium

$$
\pi\left(s_{i}\right)=(w+\delta) \frac{\theta_{i}}{\theta_{i}+N}
$$

To simplify notation in what follows, we define $\beta_{i}=\theta_{i} /\left(\theta_{i}+N\right)$ and let $\bar{\beta}=\sum_{j=1}^{N} \beta_{j} / N$.Thus,

(5) $\pi\left(s_{i}\right)=\beta_{i}(w+\delta)$.

We now turn to the equilibrium choice of wages by workers in Stage II, given the responses in (5) for the Stage IV outcome. We think of there being a continuum of workers on the unit interval. The utility function of worker $j, j \in[0,1]$, is given by

$$
-\left(w_{j}-\pi\right)^{2}
$$

The interpretation is that workers have a target real wage, normalized to be zero. Optimal wage setting then implies that wages must solve the following fixed point problem:

$$
w(\theta)=\frac{1}{N} \sum_{j=1}^{N} \pi\left(s_{j}, \theta, w(\theta)\right) .
$$

Substituting the expressions for $\pi(s)$ from (5) gives

$$
w=\frac{1}{N} \sum_{j=1}^{N} \beta_{j}(w+\delta)=\bar{\beta}(w+\delta) .
$$

Thus, it follows that

(6) $w=\delta \frac{\bar{\beta}}{1-\bar{\beta}}$.

and that $w+\delta=\delta /(1-\bar{\beta})$. Thus, the state contingent inflation and output levels along the equilibrium path are given by

$$
\pi\left(s_{i}\right)=(w+\delta) \beta_{i}=\frac{\delta \beta_{i}}{1-\bar{\beta}}
$$


and,

$$
y_{i}\left(s_{i}\right)=\bar{y}+\pi\left(s_{i}\right)-(w+\delta)=\bar{y}+(w+\delta) \beta_{i}-(w+\delta)=\bar{y}-(w+\delta)\left(1-\beta_{i}\right) .
$$

Thus, in equilibrium,

$$
y_{i}\left(s_{i}\right)=\bar{y}-\frac{\delta\left(1-\beta_{i}\right)}{1-\bar{\beta}}
$$

while $y_{j}\left(s_{i}\right)=\bar{y}$ for $j$ different from $i$.

Finally, we consider the Stage I choices of the delegate types, $\theta_{i}$. The problem for government $i$, is

$$
\operatorname{Max}_{\theta_{i}} \frac{1}{N} \sum_{j=1}^{N}\left[-\frac{1}{2}\left(y_{i}\left(s_{j}\right)-\bar{y}\right)^{2}-\frac{1}{2} \pi\left(s_{j}\right)^{2}\right]
$$

where $\theta_{i}$ enters the problem indirectly through the equilibrium choices of $y_{i}(s)$ and $\pi(s)$.

Since $\beta_{i}=\theta_{i} /\left(N+\theta_{i}\right)$ is a monotone relationship, we can instead view the governments as choosing $\beta_{i}$. Recalling that $y_{i}\left(s_{j}\right)=\bar{y}$ for $j \neq i$, substituting from (7) and (8), we can rewrite the government $i^{\prime}$ s problem as

$$
\operatorname{Max}_{\beta_{i}}-\frac{1}{2 N}\left[\left[\frac{\delta\left(\beta_{i}-1\right)}{1-\bar{\beta}}\right]^{2}+\sum_{j}\left[\frac{\delta \beta_{j}}{1-\bar{\beta}}\right]^{2}\right]
$$

We restrict our attention to the case in which $N$ is large. That is, we will assume that $N$ is large enough so that the choice of the delegate by any individual country has only a negligible effect on the 'average' characteristics of the committee. Formally, we assume that $\frac{\partial \bar{\beta}}{\partial \beta_{i}} \approx 0$.

Using this assumption to simplify the government's problem, differentiating (9) and simplifying gives the following first order condition for the choice of delegate type $\delta\left(\beta_{i}-1\right)+\delta \beta_{i}=0$. It follows that $\beta_{i}=\frac{1}{2}$ for all $i$, and, hence, $\bar{\beta}=\frac{1}{2}$ as well. From the definition of $\bar{\beta}$, we have that $\theta_{i}=N$ for all $i$.

From (7) we have that $\pi\left(s_{i}\right) \approx \delta>0$ and from (8), we have that $y_{i}\left(s_{i}\right) \approx$ $\bar{y}-\delta$, and that $y_{i}\left(s_{j}\right)=\bar{y}$ if $i \neq j$. We summarize this discussion as a Proposition:

Proposition 1: (The Extreme Nature of Strategic Delegation). If $N$ is large, equilibrium outcomes without commitment and with strategic delegation are given as follows 
(i) $\quad \theta_{i}=N$ for all $i$,

(ii) $\quad \pi\left(s_{i}\right)=\delta$, for all $i$,

(iii) $\quad y_{i}\left(s_{i}\right)=\bar{y}-\delta, y_{i}\left(s_{j}\right)=\bar{y}$ if $i \neq j$, for all $i$.

\section{Inefficiency due to Strategic Delegation}

Next we show that without the possibility of strategic delegation, outcomes are better. The economy without strategic delegation is identical to that considered above except that for each $i, \theta_{i}$ is constrained to be the same as the type of the government, namely 1 . Then $\beta_{i}=1 /(N+1)$. From (7), we then have that for large $N, \pi\left(s_{i}\right) \approx 0$ for all $i$. From (8), we have that $y_{i}\left(s_{i}\right) \approx \bar{y}-\delta$, and that $y_{i}\left(s_{j}\right)=\bar{y}$ if $i \neq j$. Indeed, as we show these outcomes also turn out to be the efficient outcomes with commitment.

With commitment, we say that outcomes are efficient if monetary policy maximizes the sum of the payoffs of the government. That is efficient outcomes require that we choose a function, $\pi(s)$ to maximize:

$$
\sum_{i=1}^{N} U_{i}=-\frac{1}{2 N} \sum_{i=1}^{N} \sum_{j=1}^{N}\left[\left(y_{i}\left(s_{j}\right)-\bar{y}\right)^{2}+\frac{1}{2} \pi\left(s_{j}\right)^{2}\right]
$$

subject to the constraint that $w=E(\pi)$. Given the symmetry of the problem, it is clear that outcomes will be the same in every state. Substituting from (1) and (2), we then have that efficient outcomes solve

$$
\operatorname{Max}_{\pi}-\frac{1}{2 N} \sum_{i=1}^{N}\left[(\pi-w-\delta)^{2}+N \pi^{2}\right]
$$

subject to $w=\pi$. Clearly, the solution is to set $\pi=0$. Output is given by $y_{i}\left(s_{i}\right)=\bar{y}-\delta, y_{i}\left(s_{j}\right)=\bar{y}$ if $i \neq j$, for all $i$.

Summarizing,

Proposition 2. (Outcomes are efficient without strategic delegation) Efficient outcomes with commitment and, when $N$ is large equilibrium outcomes without commitment and without strategic delegation are given by

(i) $\quad \pi\left(s_{i}\right)=0$, for all $i$,

(iii) $\quad y_{i}\left(s_{i}\right)=\bar{y}-\delta, y_{i}\left(s_{j}\right)=\bar{y}$ if $i \neq j$, for all $i$. : 
Comparing Propositions 1 and 2, we have established that strategic delegation leads to inefficiently high inflation and exactly the same levels of output in each country and in each state. We emphasize that lack of commitment plays no role in the inefficiency of the equilibrium outcomes under strategic delegation. Notice that if governments could not delegate monetary policy to a representative whose type is systematically different from theirs, even without commitment outcomes are approximately efficient for large $N$.

\section{Strategic Delegation with Perfectly Corre- lated Shocks}

In this section, we show that with perfectly correlated shocks, governments in the monetary union strategically delegate monetary policy but that the equilibrium is efficient. This result highlights the importance of imperfectly correlated shocks in creating a strategic delegation problem.

Suppose now that the economy has two states, indexed by $s=0$ and $s=1$. Let $p_{0}$ denote the probability of state 0 and $p_{1}$ denote the probability of state 1 . We interpret $s=0$ as corresponding to a situation in which none of the countries is in a recession and $s=1$ as corresponding to a situation in which all countries are in a recession. Formally, in state 0, output is given by $\bar{y}$ in all countries and in state 1 , output is given by

$$
y_{i}(1)=\min \left[\bar{y}+\pi(1)-w_{i}-\delta, \bar{y}\right]
$$

where $\pi(1)$ denotes the inflation rate in state 1 . Preferences are given by the analogs of (3) and (4).

We solve for the equilibrium of the game using backward induction. Consider first the situation after the shocks are realized. If the state is $s=1$, at the monetary policy setting stage, the inflation rate is chosen to solve

$$
\operatorname{Max}_{\pi} \sum_{j=1}^{N}\left[-\frac{\theta_{i}}{2}\left(y_{i}(1)-\bar{y}\right)^{2}-\frac{1}{2} \pi(1)^{2}\right]
$$

The first order condition for this problem is

$$
-\sum_{j=1}^{N}\left[\theta_{i}(\pi-w-\delta)+\pi\right]=0 .
$$


This condition can be written as

$$
\pi \sum_{j=1}^{N}\left(\theta_{i}+1\right)=(w+\delta) \sum_{j=1}^{N} \theta_{i} .
$$

It follows that

$$
\pi(1)=(w+\delta) \frac{\sum_{j=1}^{N} \theta_{i}}{N+\sum_{j=1}^{N} \theta_{i}}=\hat{\beta}(w+\delta) .
$$

where

$$
\hat{\beta}=\frac{\sum_{j=1}^{N} \theta_{i}}{N+\sum_{j=1}^{N} \theta_{i}} .
$$

If the state $s=0$, clearly the optimal inflation choice is $\pi(0)=0$.

We now turn to the equilibrium choice of wages by workers in Stage II, given that inflation rates are set optimally. Again, optimal wage setting implies that wages must solve the following fixed point problem:

$$
w(\theta)=\sum_{j=0}^{1} p\left(s_{j}\right) \pi\left(s_{j}, \theta, w(\theta)\right) .
$$

Substituting the expressions for $\pi(1)$ from (11) and $\pi(0)=0$, gives $w=$ $p_{1} \hat{\beta}(w+\delta)$. Thus, it follows that $\left.w=\delta \hat{\beta} p_{1} / 1-\hat{\beta} p_{1}\right)$ and that $w+\delta=$ $\delta /\left(1-\hat{\beta} p_{1}\right)$. Thus, a summary of the state contingent inflation and output levels along the equilibrium path is the following. If the state is $s=0, y_{i}=\bar{y}$ for all $i$, and $\pi(0)=0$. If the state is $s=1$,

$$
\pi(1)=(w+\delta) \hat{\beta}=\frac{\delta \hat{\beta}}{1-\hat{\beta} p_{1}}
$$

and,

$$
y_{i}(1)=\bar{y}+\pi(1)-(w+\delta)=\bar{y}+(w+\delta) \hat{\beta}-(w+\delta)=\bar{y}-(w+\delta)(1-\hat{\beta}) .
$$


Thus,

$$
y_{i}(1)=\bar{y}-\frac{\delta(1-\hat{\beta})}{1-\hat{\beta} p_{1}} \text { for all } i .
$$

Consider the Stage I choices of the representative types, $\theta_{i}$. Since output in state 0 is $\bar{y}$ and inflation in state 0 is 0 , the problem for government $i$, is

$$
\operatorname{Max}_{\theta_{i}} p_{1}\left[-\frac{1}{2}\left(y_{i}(1)-\bar{y}\right)^{2}-\frac{1}{2} \pi(1)^{2}\right]
$$

where $\theta_{i}$ enters the problem indirectly through the equilibrium choices of $y_{i}(s)$ and $\pi(s)$. It is easy to show that the solution to this problem has $\hat{\beta}$ strictly less than $1 / 2$. This result implies that in the symmetric equilibrium, $\theta_{i}$ is strictly less than one. That is, the selected delegate is (strictly) more conservative than the governments themselves, but not as conservative as is obtained in the standard Rogoff formulation. In fact, one can show that

$$
\pi(1)=\frac{\delta\left(1-p_{1}\right)}{1+\left(1-p_{1}\right)^{2}}
$$

and that $y_{i}(1)>\bar{y}-\delta$ if $p_{1}<1$. This outcome yields higher welfare than in an environment without strategic delegation. Without such delegation, $\theta_{i}$ is constrained to be 1 and the rest of the game is unchanged. To see that strategic delegation raises welfare, consider choosing an efficient allocation with the constraint that $\pi(0)=0$. The solution to this problem is clearly the same as the solution to the problem of choosing $\theta$. Strategic delegation yields higher welfare for exactly the same reason as in Rogoff (1985). It allows governments to solve the lack of commitment problem although imperfectly.

\section{Strategic Delegation with Economic Link- ages}

To see how economic linkages between countries affect strategic delegation, we will consider a modification of the benchmark model in which all output risk is shared equally across all countries in the union. We maintain the same formulation for output as in our benchmark model but now assume that 
consumption in country $i$ in state $s$ is the average output across countries. We then have the same model as in our benchmark case except that

$$
y_{i}\left(s_{j}\right)=\bar{y}+\frac{1}{N}\left[\pi\left(s_{j}\right)-w-\delta\right] .
$$

where $y_{i}$ now denotes consumption in country $i$.

The preferences over consumption are the same as in our benchmark model. In this modification, at the monetary policy setting stage, given the delegate types, inflation is chosen to solve

$\operatorname{Max}_{\pi\left(s_{j}\right)}-\sum_{i=1}^{N}\left\{\frac{\theta_{i}}{2}\left(y_{i}\left(s_{j}\right)-\bar{y}\right)^{2}+\frac{N}{2} \pi\left(s_{j}\right)^{2}\right\}=-\sum_{i=1}^{N}\left\{\frac{\theta_{i}}{2}\left[\frac{1}{N}\left(\pi\left(s_{j}\right)-w-\delta\right)^{2}\right]+\frac{N}{2} \pi\left(s_{j}\right)^{2}\right\}$.

The first order condition for this problem is:

$$
-\frac{\bar{\theta}}{N}\left[\pi\left(s_{j}\right)-w-\delta\right]=N \pi\left(s_{j}\right)
$$

where $\bar{\theta}=\frac{1}{N} \sum \theta_{i}$.

It follows that

$$
\pi\left(s_{j}\right)=\pi=\frac{\frac{\bar{\theta}}{N}[w+\delta]}{N+\frac{\bar{\theta}}{N}} \text { for all } j .
$$

Thus, it follows that

$$
w=E\left(\pi\left(s_{j}\right)\right)=\pi\left(s_{j}\right)=\pi=\frac{\frac{\bar{\theta}}{N}[w+\delta]}{N+\frac{\bar{\theta}}{N}} .
$$

It follows then that $w(N+\bar{\theta} / N)=\frac{\bar{\theta}}{N}[w+\delta]$. Hence, $w=\pi=\bar{\theta} \delta / N^{2}$ and $\pi-w=0$ for all $s$.

Thus, the government's problem is given by

$$
\operatorname{Max}_{\theta_{i}}-\frac{1}{2} \sum_{j} \frac{1}{N}\left[\left(y_{i}\left(s_{j}\right)-\bar{y}\right)^{2}+\pi\left(s_{j}\right)^{2}\right],
$$

where $y_{i}\left(s_{j}\right)$ and $\pi\left(s_{j}\right)$ depend on the vector of chosen types.

Since in this case, $\pi\left(s_{j}\right)=\pi=w$ for all $j$, and

$$
y_{i}(s)=\frac{N-1}{N} \bar{y}+\frac{1}{N}\left[\bar{y}+\pi\left(s_{j}\right)-w-\delta\right]=\bar{y}+\frac{1}{N}\left[\pi\left(s_{j}\right)-w-\delta\right],
$$


it follows that for all $y_{j}\left(s_{j}\right)=\bar{y}+\frac{1}{N} \delta$ for all $i$ and $j$.

Thus the government's problem reduces to

$\operatorname{Max}_{\theta_{i}}-\frac{1}{2} \sum_{j} \frac{1}{N}\left[\left(\bar{y}+\frac{1}{N} \delta-\bar{y}\right)^{2}+\pi\left(s_{j}\right)^{2}\right]=-\frac{1}{2} \sum_{j} \frac{1}{N}\left[\left(\frac{\delta}{N}\right)^{2}+\pi\left(s_{j}\right)^{2}\right]$.

Here, the delegate type $\theta_{i}$ only enters government $i$ 's problem through its effect on inflation. It follows that since

$$
\pi\left(s_{j}\right)=\pi=\frac{\frac{\bar{\theta}}{N}[w+\delta]}{N+\frac{\bar{\theta}}{N}} \text { for all } j,
$$

government $i$ chooses $\theta_{i}$ to minimize $\pi$ taking as given the other choices of $\theta_{j}$. This is to set $\theta_{i}=0$. Thus, in equilibrium, $\theta_{i}=\bar{\theta}=0$ for all $i$, and hence, $\pi=w=0$ for all $s$.

Thus, it follows that if the economies in the union are sufficiently linked economically, the Rogoff result obtains, strategic delegation does not arise and the outcome is efficient.

Although we have analyzed the effects of full insurance here, the analysis can be easily extended to cases where labor is mobile and the capital in each country is owned by households in all countries. With perfect factor mobility, incomes are equated across countries and the analysis with risk sharing applies without change.

The analysis with perfectly correlated shocks clearly applies without change to a single country which is not in a monetary union. Thus, the results in this section also show that with strategic delegation, outcomes in a monetary union are worse than those without a monetary union. Of course, we have abstracted from other benefits of monetary unions in focusing on the costs due to strategic delegation.

\section{Strategic Delegation with a Linear Phillips Curve}

Next, we analyze the role played by our assumption that the Phillips Curve is nonlinear. Assume that the Phillips Curve is linear for all countries for all states. That is,

$$
y_{j}\left(s_{i}\right)=\bar{y}+\pi\left(s_{i}\right)-w \text { if } j \neq i, \text { and } y_{i}\left(s_{i}\right)=\bar{y}+\pi\left(s_{i}\right)-w-\delta
$$


In state $s_{i}$, at the monetary policy setting stage, inflation is chosen to solve

$$
\operatorname{Max}_{\pi} \sum_{j=1}^{N}\left[-\frac{\theta_{j}}{2}\left(y_{j}\left(s_{i}\right)-\bar{y}\right)^{2}-\frac{1}{2} \pi\left(s_{i}\right)^{2}\right]
$$

The first order condition for this problem can be written as:

$$
\pi\left(s_{j}\right)=\frac{\theta_{j} \delta+w \sum_{i=1}^{N} \theta_{i}}{N+\sum_{i=1}^{N} \theta_{i}}
$$

Thus, since $w=E(\pi)$ and all states are equally likely, it follows that:

$$
w=\frac{1}{N} \sum_{j=1}^{N} \pi\left(s_{j}\right)=\frac{1}{N} \sum_{j=1}^{N} \frac{\theta_{j} \delta+w \sum_{i=1}^{N} \theta_{i}}{N+\sum_{i=1}^{N} \theta_{i}}
$$

Solving for the wage rate $w$, we obtain

$$
w=\frac{\delta}{N^{2}} \sum_{j=1}^{N} \theta_{j} .
$$

Substituting in (13) we have that,

$$
\pi\left(s_{i}\right)=\frac{\theta_{i} \delta+\frac{\delta}{N^{2}}\left(\sum_{i=1}^{N} \theta_{i}\right)^{2}}{N+\sum_{j=1}^{N} \theta_{j}} .
$$

Note that in a symmetric equilibrium in which all delegate types are identical, we have

$$
\pi=w=\frac{\delta \theta}{N}
$$


Substituting for inflation and the wage rate in (12), we obtain that output in state $s_{j}$ in country $i$ for $i \neq j$ is given by,

$$
y_{i}\left(s_{j}\right)=\bar{y}+\frac{\theta_{j} \delta+\frac{\delta}{N^{2}}\left(\sum_{k=1}^{N} \theta_{k}\right)^{2}}{N+\sum_{k=1}^{N} \theta_{k}}-\frac{\delta}{N^{2}} \sum_{k=1}^{N} \theta_{k}=\bar{y}+\frac{\theta_{j} \delta-\frac{\delta}{N} \sum_{k=1}^{N} \theta_{k}}{N+\sum_{k=1}^{N} \theta_{k}}
$$

and for country $j$,output is given by

$$
y_{j}\left(s_{j}\right)=\bar{y}+\frac{\theta_{i} \delta+\frac{\delta}{N} \sum_{k=1}^{N} \theta_{k}}{N+\sum_{k=1}^{N} \theta_{k}}-\delta .
$$

Note that in a symmetric equilibrium $y_{i}\left(s_{j}\right)=\bar{y}$ and $y_{j}\left(s_{j}\right)=\bar{y}-\delta$.

Turning to the stage I choice of the delegate type $\theta_{i}$, the government in country $i$ chooses $\theta_{i}$ to solve:

$$
\operatorname{Max}_{\theta_{i}} \frac{1}{N} \sum_{j=1}^{N}\left[-\frac{1}{2}\left(y_{j}\left(s_{j}\right)-\bar{y}\right)^{2}-\frac{1}{2} \pi\left(s_{j}\right)^{2}\right]
$$

The first order condition from this problem is:

$$
-\sum_{j \neq 1}\left[\left(y_{i}\left(s_{j}\right)-\bar{y}\right) \frac{\partial y_{i}\left(s_{j}\right)}{\partial \theta_{i}}+\pi\left(s_{j}\right) \frac{\partial \pi\left(s_{j}\right)}{\partial \theta_{i}}\right]-\left[\left(y_{i}\left(s_{i}\right)-\bar{y}\right) \frac{\partial y_{i}\left(s_{i}\right)}{\partial \theta_{i}}+\pi\left(s_{i}\right) \frac{\partial \pi\left(s_{i}\right)}{\partial \theta_{i}}\right]=0 .
$$

In a symmetric equilibrium, this first order condition becomes

$$
-(N-1) \pi \frac{\partial \pi\left(s_{j}\right)}{\partial \theta_{i}}+\delta \frac{\partial y_{i}\left(s_{i}\right)}{\partial \theta_{i}}-\pi \frac{\partial \pi\left(s_{i}\right)}{\partial \theta_{i}}=0
$$

Differentiating (14) and (15), simplifying and substituting from (14) and (15), we obtain that in a symmetric equilibrium

$$
\delta\left(\delta-\frac{\delta}{N}\right)=(N-1) \pi \frac{2 \delta \theta}{N}+\pi\left(\delta+\frac{2 \delta \theta}{N}\right) .
$$


Substituting for the result that $\pi=\delta \theta / N$, we obtain that when $N$ is large we have

$$
2 \delta \theta^{2}+\delta \theta=N \delta
$$

It follows that $\theta \approx \sqrt{\frac{N}{2}}$. Recall that in a symmetric equilibrium, $\pi=$ $\frac{\delta \theta}{N} \approx \frac{\delta}{N} \sqrt{\frac{N}{2}}$. Thus, $\pi \longrightarrow 0$ as $N \longrightarrow \infty$.

Thus, although the strategic delegation problem becomes more severe as $N \longrightarrow \infty$ in the sense that $\theta \longrightarrow \infty$, the equilibrium levels of output and inflation converge to the efficient levels.

\section{Conclusions}

In this paper, we have analyzed strategic delegation in monetary unions. We have shown that strategic delegation arises and leads to inefficient outcomes if shocks across countries are not perfectly correlated, economic linkages are not strong and if the Phillips curve is nonlinear. The possibility of inefficiency arising from strategic delegation reinforces the need for constitutional strictures which constrain monetary policy in monetary unions. 


\section{References}

Barro, Robert J. and David B. Gordon. 1983. A Positive Theory of Monetary Policy in a Natural Rate Model. Journal of Political Economy 91 (4, August), 589-610.

Beetsma, Roel and Harald Uhlig. 1999. An Analysis of the Stability and Growth Pact. Economic Journal 109 (458, October), 546-71.

Chari, V. V. Larry Jones and Ramon Marimon. 1997. The Economics of Split Voting in Representative Democracies American Economic Review, 87, (December),. 957-976.

Chari, V. V. and Patrick J. Kehoe. 2002. Time Inconsistency and FreeRiding in a Monetary Union. Federal reserve Bank of Minneapolis Staff Report 308.

Chari, V. V. and Patrick J. Kehoe. 2003. On the Desirability of Fiscal Constraints in a Monetary Union. Federal reserve Bank of Minneapolis Staff Report 330.

Cooper, Russell W. and Hubert Kempf. 2001. Dollarization and the Conquest of Hyperinflation in Divided Societies. Federal Reserve Bank of Minneapolis Quarterly Review 25 (3, Summer), 3-12.

Dixit, Avinash and Luisa Lambertini. 2001. Monetary-Fiscal Policy Interactions and Commitment versus Discretion in a Monetary Union. European Economic Review 45 (4-6, May), 977-87.

Kydland, Finn E. and Edward C. Prescott. 1977. Rules Rather Than Discretion: The Inconsistency of Optimal Plans. Journal of Political Economy 85 (3, June), 473-91.

Rogoff, Kenneth. 1985. The Optimal Degree of Commitment to an Intermediate Monetary Target, Quarterly Journal of Economics 100 (November), 1169-1189

Uhlig, Harald. 2002. One Money, But Many Fiscal Policies in Europe: What are the Consequences? Manuscript, Humboldt University, Berlin. 